\title{
AS POLÍTICAS EDUCACIONAIS E O ESTÁGIO CURRICULAR SUPERVISIONADO NO CURSO DE GRADUAÇÃO EM ENFERMAGEM
}

\author{
EDUCATIONAL POLICIES AND THE SUPERVISED CURRICULAR INTERNSHIP IN THE UNDERGRADUATE \\ NURSING COURSE
}

LAS POLIITICAS EDUCACIONALES Y LA PASANTÍA CURRICULAR SUPERVISADA EN EL CURSO

DE GRADO EN ENFERMERÍA

\author{
Ana Lúcia Marran ${ }^{1}$ \\ Paulo Gomes Lima ${ }^{2}$ \\ Maria Helena Salgado Bagnato ${ }^{3}$
}

Resumo $\mathrm{O}$ artigo discute as políticas de educação e o estágio curricular supervisionado no curso de graduação em enfermagem, a influência da reestruturação produtiva e da reforma do Estado capitalista no ensino superior brasileiro. Por se tratar de um estudo reflexivo, buscou-se como referencial de discussão a literatura da área, bem como os norteamentos trazidos pelas legislações do estágio curricular supervisionado e do ensino de enfermagem. No processo histórico da profissão do enfermeiro, destacam-se o cuidado com a prática profissional e os modos possíveis de apropriação da identidade desse profissional. Assim, o estágio é visto como parte indispensável no seu processo de formação; por meio dele podem-se desenvolver habilidades e competências próprias do enfermeiro. O estágio curricular supervisionado não deve ser visto somente como uma exigência do mundo capitalista, pois é possível formar um enfermeiro capaz de refletir sobre suas condições materiais de existência utilizando a prática reflexiva na articulação entre ensino e serviço. Palavras-chave estágio curricular; enfermagem; políticas de educação.
Abstract The article discusses the educational policies and the supervised curricular internship in the undergraduate nursing course, in addition to the influence of productive restructuring and of the reform of the capitalist State on Brazilian higher education. Because it is a reflective study, the literature on the area and the guidance introduced by the laws concerning the supervised curricular internship and nursing education were used as references. In the historical process of the nursing profession, the care with the professional practice and the possible modes of appropriation of this professional identity are under the limelight. Thus, the internship is seen as an essential part of the training process; the skills required of the nurse can be learned through it. The supervised curricular internship should not be seen merely as a requirement of the capitalist world, as it is possible to train a nurse who can reflect on his or her material conditions of existence using the reflective practice in linking teaching and work.

Keywords internship; nursing; education policies. 


\section{Introdução}

O início do século XXI é marcado por significativas mudanças no campo das políticas educacionais, particularmente nas discussões e regulamentações no âmbito do estágio curricular supervisionado (ECS) nos cursos de graduação, alcançando considerável reestruturação na formação profissional. Embora condicionado pelo processo de reestruturação produtiva e reforma do Estado capitalista, o ECS também foi mediatizado pelas tensões sociais e aspirações da comunidade acadêmica quanto à tipologia de trabalhador a ser formado. Com isso, o ensino de enfermagem segue na busca do pensamento complexo, almejando um estudante crítico-reflexivo capaz de atuar em situações diversas, propondo soluções aos problemas encontrados.

É nesse contexto conflituoso que o estágio ganha destaque no processo de formação na educação superior, tornando-se mais presente e dispondo de maior organização nas matrizes curriculares dos cursos, inicialmente após a elaboração das Diretrizes Curriculares Nacionais para diversas áreas de atuação e depois por conta da lei n. 11.788/2008, conhecida como 'nova lei de estágios'. Em nível específico, há a resolução do Conselho Nacional de Educação/Câmara de Educação Superior (CNE/CES) n. 3, de 7 de novembro de 2001 (Brasil, 2002), que instituiu as Diretrizes Curriculares Nacionais para o curso de Graduação em Enfermagem no Brasil (DCNENFs) (Brasil, 2001), considerando o ECS como um dos elementos fundamentais na formação acadêmica, o que contribui para a necessidade da discussão dessa temática.

Sabendo que a leitura de um objeto de estudo não se restringe ao olhar imediato sobre o seu arranjo atual - como se tivesse em si respostas autoexplicativas na relação causa-efeito - mas, ao contrário, solicita contínua recorrência aos condicionantes sócio-históricos que contribuíram para o seu surgimento ou novo arranjo entre rupturas, permanências ou superações, o desenvolvimento deste artigo centrar-se-á na discussão sobre as políticas de educação e o ECS no curso de graduação em enfermagem, a influência da reestruturação produtiva e da reforma do Estado capitalista no ensino superior brasileiro, principalmente no que se refere ao estágio curricular supervisionado. 4

\section{Políticas educacionais a partir da década de 1990: condicionantes sócio-históricos}

O contexto atual das políticas educacionais no Brasil pode ser compreendido a partir de pelo menos dois eixos articulados: o primeiro, por meio do rearranjo dos modos de produção do capitalismo, marcado pelo processo de globalização e intensificação das discussões sobre as políticas públicas da educação e seu papel estratégico na preparação das populações para o novo 
arranjo econômico, particularmente na década de 1990 no caso brasileiro (Dourado, Catani e Oliveira, 2003; Lima, 2011b). O segundo eixo é aquele mobilizado pelas tensões e solicitações advindas de distintos agrupamentos sociais, compreendendo que as políticas públicas e, nesse caso, as educacionais, "não são estáticas ou fruto de iniciativas abstratas, mas estrategicamente empregadas no decurso dos conflitos sociais" (Shiroma, Moraes e Evangelista, 2007, p. 8). E para ter validade entre elaboração e implementação, isto é, para ser viável de fato, deve derivar-se de uma rede de relações (Rothen, 2004; Barreyro e Rothen, 2008).

Na década de 1990, dentre outros eventos, em consonância com a agenda neoliberal, ocorre a reforma do Estado. Seguiu-se a reforma do sistema educativo no Brasil e sua prospecção em nível de elevar as condições de acesso, aprimorar a qualidade da educação como um todo e fomentar a engenharia da competividade científica e tecnológica como esteio do desenvolvimento econômico do país no processo de globalização, estabelecendo um processo de monitoramento e avaliação permanentes para o alcance do referencial pretendido pela internacionalização do capital (Lima, 201 la).

Esse ideário dos países dominantes, vindo dentre outras formas por meio das agências multilaterais com seus numerosos programas de assistência, indutores de políticas e 'fazeres' ideológicos e instrumentais, passa a ser incorporado nas políticas públicas dos demais países (Ramão, 2008; Xavier e Deitos, 2006).

Siqueira e Neves (2006) afirmam que, para a adequação dos futuros profissionais que atendem às necessidades do capitalismo e seu funcionamento, dois ingredientes são indispensáveis: o incremento de sua capacitação técnica visando aumentar a produtividade e a competitividade; e uma nova capacitação com o objetivo de instaurar uma nova cultura única com base na conciliação de classes, visando 'humanizar' as relações.

Nesse contexto, a formação que se pretende oferecer aos estudantes, entre eles os do curso de graduação em enfermagem, deve ser embasada em conhecimentos que lhes permitam desenvolver a capacidade de identificar problemas, seguida pela habilidade de propor soluções por meio do desenvolvimento do raciocínio crítico e da comunicação (Barlem et al., 2012).

O ponto de partida para a inserção do Brasil nessa nova lógica foi inaugurado com a aprovação da Constituição Federal em 1988, que incorporou as demandas sociais, resultado das mobilizações pela democratização da educação e da descentralização financeira e decisória (Krawczyk e Vieira, 2008), sem deixar de contemplar as demandas da reestruturação produtiva, calcadas no neoliberalismo e que já haviam sido introduzidas nos países latino-americanos vizinhos.

Em 1990, por ocasião da realização da Conferência Mundial sobre ‘Educação para Todos' na cidade de Jomtien, na Tailândia, foi apresentada uma 'visão para o decênio de 1990', que inaugurou um grande projeto de educação em 
nível mundial para aquela década que estava começando, financiado pelas agências multilaterais como a Organização das Nações Unidas para a Educação, a Ciência e a Cultura (Unesco), o Fundo das Nações Unidas para a Infância (Unicef) e o Banco Mundial (Frigotto e Ciavatta, 2003), e propunha "maior equidade social nos países mais pobres e populosos do mundo" (Oliveira, 1999, p. 73).

A partir da referida conferência, o Brasil estabelece o Plano Decenal de Educação para Todos (1993-2003), que se configurou para Silva Júnior (2002) como a expressão brasileira de adesão ao movimento mundial orquestrado por Unesco/Banco Mundial e assumido como referência para as políticas públicas de educação, resultando em reformas que atingiram todos os níveis e modalidades de ensino.

Krawczyk e Vieira (2008) acrescentam que, no ideário da reforma educacional acontecida no Brasil, buscou-se consolidar as diretrizes internacionais na constituição de uma nova forma de gestão da educação, segundo o modelo da 'revolução da administração gerenciada', da qual a escola no Brasil não estaria isenta.

Esse entendimento estende-se para a reforma da educação que se consubstanciou na Lei de Diretrizes e Bases da Educação Nacional (LDB), lei n. 9.394/1996 (Brasil, 1996a), e estabelecia uma nova organização e gestão do sistema educacional. Nesse caso, era necessária a reformatação ou 'reorientação' do currículo da educação nacional em seus distintos níveis e modalidades conforme o novo contexto econômico e social, como afirmam Krawczyk e Vieira (2008) e Camargo (2009).

Os parâmetros curriculares nacionais são patamarizados na flexibilização, na ênfase aos conteúdos considerados necessários ao mundo do trabalho e nos conteúdos básicos para as atividades práticas produtivas (Fogaça, 1999). Vale dizer que o Brasil não somente acompanhava o movimento e o 'sucesso' das conquistas da realidade dos países desenvolvidos, mas também estabelecia os fundamentos para a sua transposição para a realidade brasileira, a exemplo do que já haviam feito os países latino-americanos vizinhos. Consequentemente, pela efervescência política e econômica e pela legitimação de discursos quanto ao desenvolvimento científico e tecnológico, os Parâmetros Curriculares Nacionais advogavam uma educação coerente com o processo de acumulação mundial, uma vez que há exigência de novas tipologias de produção e de mão de obra qualificada - e com relação a esta última, de que os trabalhadores se mostrem mais "criativos e versáteis, capazes de entender o processo de trabalho como um todo, dotados de autonomia e iniciativa para resolver problemas em equipe e para utilizar diferentes tecnologias e linguagens" (Brasil, 1998, p. 27).

Nas reformas educacionais, a educação superior busca implementar uma nova política, associando flexibilidade, competitividade e avaliação. Nesse ínterim, a flexibilização tem a intenção de trazer para as instituições 
de ensino superior (IES) a ideia de que na elaboração ou reestruturação de seus currículos, além de suas peculiaridades, devam se preocupar com as demandas do mundo do trabalho, pois é fundamental ter consciência de qual a visão de mundo e de trabalho que pretendem desenvolver nos alunos (Camargo, 2009). Esse olhar não passaria despercebido pelas solicitações sociais, tampouco seria contemplado em sua totalidade, uma vez que situado num processo de acordos de diversos interesses.

\section{A formação profissional e o estágio curricular supervisionado na primeira década do século XXI}

Por um lado admitimos que, conforme Segnini (2000) denuncia, a educação e a formação profissional são fundamentais para o momento que vive o capitalismo, por serem capazes de possibilitar a competitividade e intensificar a concorrência e adaptar trabalhadores às mudanças técnicas, minimizando assim os efeitos do desemprego. Com essa expectativa, o próprio Banco Mundial traz em suas diretrizes a ideia de que a educação profissional deve estreitar seus vínculos com as atividades econômicas, visando ao alinhamento do perfil profissional com as necessidades do mercado (Fonseca, 2007). Por outro lado, não se pode ignorar o fato de que as mudanças ocorridas no mundo do trabalho exigem uma relação íntima com a formação profissional, uma vez que é por meio das instituições educacionais que se desenvolvem as inovações tecnológicas e a reorganização do trabalho, preparadoras de um novo tipo de homem adaptável ao novo modelo de desenvolvimento do capitalismo mundial (Ferretti e Silva Júnior, 2000).

Nessa diretriz, destaca-se que "ciência e trabalho, estabelecendo novas formas de relação, passam a exigir um intelectual de novo tipo (...) capaz de atuar na prática, trabalhar tecnicamente e ao mesmo tempo intelectualmente" (Kuenzer, 2001, p. 36), sob o risco de redução do homem em movimento a uma unidimensionalidade de seu processo formativo.

Nesse sentido, Gondim (2002) defende a necessidade de se estabelecer mais diálogo entre os setores da universidade, para discutir não só o respeito da responsabilidade institucional na educação para o trabalho como também seus limites, a fim de não deixar de lado sua missão histórica em decorrência do novo modelo econômico mundial. Embora sejam possíveis as leituras das induções neoliberais, há que se desenvolver a força de trabalho no sentido da possibilidade de seu despertamento de consciência, quer por ocasião da formação inicial na universidade, quer nos processos formativos via ECS que contribuam para esse fim.

Há que se pensar os condicionantes do mundo do trabalho e não meramente do mercado e das relações verticais que o transversalizam. Dessa forma, 
o ECS que, embora em algumas situações, seja reduzido ao âmbito pragmático ou emprego instrumental dos conhecimentos adquiridos em instituições educacionais de formação profissional, tem sempre a possibilidade de se constituir como elemento de reflexão sobre os processos formativos por meio da utilização de perspectivas interventivas adotadas pelo docente, conforme sustenta Gomes (2001). Daí a sua eleição como nosso objeto de discussão e inquietude neste artigo, atentando-se para a ação-reflexão-ação, que acreditamos ser indispensável para a formação de um enfermeiro crítico-reflexivo, conforme preconiza as DCNENFs.

\section{A centralidade do estágio curricular supervisionado na formação profissional}

Nesse contexto, o ECS apresenta-se como instrumento integrador entre as instituições de ensino e o campo de trabalho no ensino superior, a despeito das incursões neoliberais na diretividade de seu papel. Com isso, Souza (2009) destaca que a importância do estágio aumenta diante das profundas transformações no mundo do trabalho e do constante desenvolvimento científico e tecnológico, provocando o acirramento das discussões sobre o tema e instigando a universidade a repensar seu processo formador.

É nessa perspectiva que se nota a presença do estágio em quase todas as Diretrizes Curriculares Nacionais para os mais variados cursos, garantindo uma porcentagem significante da carga horária total, como é o caso das graduações da área da saúde. Entre esses cursos está a enfermagem, pois além das horas teóricas e práticas, é previsto que $20 \%$ da carga horária sejam destinados ao ECS (Brasil, 2001), assim como as licenciaturas, que têm a carga horária do estágio obrigatório aumentada de trezentas para quatrocentas horas (resolução CNE/CP n. 2/2002).

Vale lembrar que a Conferência Mundial sobre Educação Superior de 1998 trata o estágio como um meio de comunicação e cooperação entre o ensino superior e o mundo do trabalho, com uma orientação de diretividade instrumental. Pressupõe que as instituições formadoras devem proporcionar ao estudante diversas experiências no ambiente de trabalho respondendo às solicitações do mercado. O relatório dessa conferência evidencia a preocupação em aproximar cada vez mais a educação das exigências no novo contexto mundial, o que fica explícito no seu artigo sétimo. ${ }^{5}$

Como vimos, desde a década de 1990 as políticas públicas de educação vêm sendo repensadas por conta dos novos processos de acumulação do capital. Nesse ínterim, o ensino superior tem colocado a discussão e os encaminhamentos sobre o ECS na pauta do dia, a exemplo da reestruturação dos perfis profissionais delineados por universidades de países capitalistas desenvolvidos, tendo como agente indutor a lógica de mercado. 
Verifica-se também a centralidade do ECS na formação profissional do estudante, que lhe confere maior domínio em determinada área de atuação, descortinando-se os saberes e fazeres necessários à instrumentalização do modus laboral pertinente, como defendem muitos estudiosos, dentre eles Souza (2009). Para esta autora, o estágio, por ser um componente do projeto pedagógico de um curso, reúne os aspectos da formação acadêmica profissional com características singulares no processo de aprendizagem no crivo da articulação e indissociabilidade de teoria e prática. Promove a interlocução entre ensinar e aprender, assim como a interação entre universidade, organizações e sociedade. Consequentemente, o ECS é um componente curricular relevante na promoção e na aproximação da academia com o ambiente 'extramuros', o mundo além da dimensão teórica, entre o processo educativo e a atuação profissional.

A compreensão do ECS como um período dedicado a um processo de ensino e de aprendizagem converte-se no reconhecimento de que, embora a formação oferecida em sala de aula seja fundamental, sozinha não é suficiente para preparar os acadêmicos para o exercício de seu ofício. Faz-se indispensável a inserção do estudante na realidade do cotidiano de sua futura profissão (Felício e Oliveira, 2008; Pimenta, 2010).

Nesse contexto, entende-se que o campo do trabalho e a academia tendem a estreitar cada vez mais seus laços, para assim formar um profissional cada vez mais preparado, inclusive para problematizar os desvios e propósitos no processo de formação do estudante e como as IES tratam essa pauta em seu cotidiano.

Para evidenciar o quão significativos são os impactos da reestruturação produtiva na formação profissional e a preocupação com a preservação do ECS como componente pedagógico indispensável na formação profissional, em especial para a formação do enfermeiro, se faz necessário realizar um breve contexto histórico das legislações sobre o estágio no Brasil e na enfermagem, que será apresentado a seguir.

\section{Contexto histórico das legislações sobre o estágio no Brasil, especialmente na formação do enfermeiro}

Desde o Brasil Colônia até meados de 1940, a vinculação entre educação e trabalho é um tema no mínimo marginalizado, uma vez que, nesse caso, a educação assumiu um caráter intelectual e humanista a serviço e à disposição da classe hegemônica (Souza, 2009). A partir dessa década, inicia-se um processo de aproximação entre educação e trabalho, bem como se corporificam a discussão e a implementação do estágio como prática profissional de aprendizagem, uma vez que os processos de produção inaugurados 
pela fase urbano-industrial o exigiam, mas como ainda era de forma incipiente, não havia qualquer legislação para respaldar o seu funcionamento.

No desdobramento desse contexto, em 1949 o ensino de enfermagem foi regulamentado, havendo a primeira reformulação do currículo conforme o decreto n. 27.426/1949, que ampliava os conteúdos e a duração dos cursos. Mas os conteúdos permaneceram se direcionando para as especificidades médicas e de nível curativo com a correspondente reprodução das atividades de ensino prático (Backes, 2000). Há que se lembrar que somente em 1961 o ensino de enfermagem tornou-se universitário, fruto da lei n. 2.995/1956 (Germano, 1993).

A fiscalização e a orientação do ensino passam a ser de responsabilidade do Conselho Federal de Educação, e uma de suas contribuições foi a fixação de um currículo mínimo para o curso de graduação em enfermagem, o qual foi regulamentado pelo parecer n. 272/1962 (Germano, 1993). Com esse novo currículo ocorre a redução dos períodos de prática, com carga horária semanal de vinte horas. O professor permaneceria no campo somente durante o período de prática. Assim, as escolas deixaram de assumir a responsabilidade pela assistência, preservando o ensino e protegendo os estudantes do trabalho precarizado (Costa e Germano, 2007).

Em 1968, ocorreu a reforma universitária. Em consequência desta, em 1972 foi constituído outro currículo de enfermagem, com ênfase nas atividades práticas com carga horária não inferior a um terço das partes profissionalizantes do curso, conforme afirma Backes (2000). Surgiu também o estágio supervisionado, que deveria ser realizado ao final do curso juntamente com a disciplina de administração aplicada à enfermagem (Costa e Germano, 2007).

Na referida década é criada a lei n. 6.494, de 1977 (Brasil, 1977), caracterizada como a primeira lei de estágio no Brasil, a qual considera estagiário o aluno regularmente matriculado e que esteja comprovadamente frequentando os cursos. E determina que para que o estágio 'curricular' se firme é necessário que haja entre a IES e a organização concedente um documento denominado 'termo de compromisso de estágio', promovendo efetivamente a aproximação entre campo de atuação profissional e educação (Souza, 2009). Vale lembrar que essa exigência não se faz aos estágios 'extracurriculares', ficando claro que os estágios em forma de ação comunitária estão isentos desse termo.

Ainda conforme o decreto n. 87.497/1982 (Brasil, 1982), em seu artigo $2^{\circ}$, a aprendizagem decorrente do estágio deve ser efetivada mediante a inserção e participação em situações reais de vida e trabalho de seu meio, sob responsabilidade e coordenação da unidade de ensino.

Essas legislações favoreceram o ensino de enfermagem, ao coibir o que acontecia em sua origem, quando os estudantes eram a força de trabalho dos 
hospitais de ensino. Embora um marco importante em se tratando de legislação normativa de estágio, há que se lembrar que o período reporta-se à ditadura militar no Brasil, cuja tônica da educação como um todo e da enfermagem estava muito atrelada ao âmbito do tecnicismo. Consequentemente, outras solicitações precisavam de encaminhamento estrutural quanto ao conjunto curricular do curso - o papel dos profissionais que atuavam nos processos formativos (docentes e técnicos), bem como a especificidade do estágio, sua delimitação e diretrizes centrais para a efetividade na formação do enfermeiro.

Tais questões seriam encaminhadas no período da redemocratização política no Brasil, como poderemos acompanhar na seção seguinte.

\section{Políticas de estágio curricular supervisionado em enfermagem: das solicitações do processo de abertura democrática aos impactos contemporâneos na educação superior}

Com a aprovação da Constituição de 1988 e consequentemente a criação do Sistema Único de Saúde (SUS), há demanda pela necessidade de se ter profissionais capacitados para atuar nesse novo sistema, que traz em seus princípios e diretrizes a universalidade, a integralidade e a hierarquia de atendimento, reorganizando a assistência à saúde, atuando da parte curativa à preventiva - investindo na atenção básica por meio da promoção de saúde e prevenção de doenças (Brasil, 1988). Isso requereria dos cursos de formação especializados demandas com perfis mais definidos, ao mesmo tempo que delimitados os âmbitos de seus processos formativos. Assim, o ensino de enfermagem, como um dos cursos superiores que reclamavam mudanças estruturais, se vê diante de um novo desafio.

Vale lembrar que as discussões sobre a criação do SUS se deram na VIII Conferência Nacional de Saúde, em 1986, na qual se discutia a reformulação do sistema de saúde nacional (movimento conhecido como Reforma Sanitária), tendo como guia as orientações de Alma-Ata. ${ }^{6}$ Em consequência das propostas da Reforma Sanitária, também em 1986 aconteceu a I Conferência Nacional de Recursos Humanas para a Saúde, que teve como destaque mudanças por parte das instituições formadoras (nesse caso, as IES) para atender o novo perfil desejado para esses profissionais (Lopes, 2011).

Por conta dessa nova disposição que o Estado brasileiro estava enfrentando, em 1994 foram organizados debates e encaminhamentos dos rumos do ensino e da possibilidade de construção do novo currículo mínimo da enfermagem (Germano, 2003). Esse currículo deveria estabelecer o ECS nos dois últimos períodos do curso, prevendo a atuação nos postos de saúde e na rede hospitalar (Costa e Germano, 2007). É nesse mesmo ano que se publica 
a lei n. 8.859 (Brasil, 1994), que vem complementar a lei de 1977, reconhecendo que as atividades de estágio só podem acontecer em locais que tenham condições de proporcionar experiências práticas na linha de formação do estagiário, destacando que o estágio precisa ser planejado, executado, acompanhado e avaliado conforme o direcionamento curricular. E dois anos depois, o decreto n. 2.080/1996 (Brasil, 1996b) dispõe que a instituição de ensino ou a organização concedente de estágio deverá providenciar o seguro de acidentes pessoais ao estagiário, pois caso ocorram danos físicos inesperados, esse aluno passa a ter o mínimo de amparo para se restabelecer e voltar às suas atividades - porque não se pode esquecer que estágio não é emprego, então o estudante não tem nenhum direito trabalhista garantido.

Quando as instituições de ensino não cumprem as formalidades necessárias à regulamentação do estágio, tal ato é caracterizado como intermediação de mão de obra, distorcendo a sua finalidade e incorrendo-se em fraude aos direitos trabalhistas. A ocorrência cotidiana dessa situação levou o Ministério do Trabalho a efetuar a notificação recomendatória n. 741/2002 (Brasil, 2002), direcionada ao Conselho de Reitores, para que este orientasse as instituições de ensino quanto ao cumprimento das legislações de estágio e, ainda, ressaltasse os objetivos do estágio e a necessidade do termo de compromisso.

Diante desse cenário em que distintas contribuições normativas vieram complementar a lei n. 6.494/77 (Brasil, 1977), notou-se em seu conjunto a fragilidade da legislação de estágio no Brasil, ao mesmo tempo que aumentavam as solicitações sobre a necessidade de se elaborar uma nova legislação que fosse capaz de prever e promover mecanismos para evitar as situações em que o estagiário fosse visto como mão de obra barata. Isso seria materializado na primeira década do século XXI.

Observa-se que simultaneamente acontecem as mudanças nas políticas que orientam a formação do enfermeiro e as que orientam o ECS de forma geral. Dessa forma, após a recomendação feita pelo Ministério do Trabalho e as imposições das agências internacionais no contexto da reestruturação produtiva sobre as políticas educacionais no Brasil, as IES despertam para a necessidade de se repensar o estágio.

Em 2002, o Fórum de Pró-Reitores de Graduação das Universidades Brasileiras (Forgrad) promove o I Encontro Nacional de Estágio, seguido por mais dois encontros nos anos seguintes. Um dos aspectos centrais na discussão refere-se à articulação teoria e prática superando as dicotomias entre elas.

Nos documentos oriundos desse encontro, a Comissão Nacional de Estágio do Forgrad em 2004 aponta o estágio como "estratégia para o questionamento, reavaliação e reestruturação curricular na medida em que oportuniza a relação teoria e prática. Assim, o estágio precisa estar integrado ao currículo do curso e acontecer" (Comissão Nacional de Estágio do Fórum de Pró-Reitores de Graduação das Universidades Brasileiras, 2004). 
O Forgrad de 2004 chamava a atenção para a importância de o estágio configurar-se como um espaço determinante da formação profissional do acadêmico. Isso só acontece com acompanhamentos mediante supervisões, ao se fazer a articulação formação inicial e a inserção social do profissional. A esse respeito, Amantéa (2004) defendia a ideia de que a supervisão de estágio deve promover a coerência entre a teoria e a prática na trilogia ação-reflexão-ação, levando o estagiário à construção de conhecimentos, habilidades e valores em articulação com a realidade e com a equipe de trabalho.

O referido fórum entendeu que, por conta do quadro e das solicitações feitas por todas as vozes comprometidas com a formação profissional de acadêmicos e outras representações educacionais, tais condições não poderiam prescindir da assinatura de termos de compromisso durante o exercício do estágio. Nesse sentido, o termo de compromisso foi entendido como o documento que define todas as atividades que serão realizadas pelo estagiário, assim como a carga horária que será cumprida e todos os deveres e direitos dos envolvidos nesse processo: instituição de ensino, organização concedente do estágio e estudante.

Não valorizar o estágio como estratégia pedagógica no interior da IES pode acarretar lacunas no processo de aprendizagem no qual o estudante se encontra, contribuindo para a desvalorização da educação superior e para a queda de qualidade na formação profissional (Souza, 2009). O Forgrad foi fundamental para que as instituições de ensino fossem ouvidas no processo de elaboração da nova legislação, pois como afirma Sobottka (2006):

Na esfera pública do mundo da vida se articula a sociedade civil, da qual fazem parte os movimentos sociais e as ONGs e outras tantas formas de reprodução cultural, para conquistar direitos sociais de cidadania. Esse é o genuíno espaço da Política, onde os cidadãos, idealmente superando diferenças que causem constrangimento, definem de forma aberta, direta e participativa, os destinos de sua vida em sociedade. Estas definições alimentam a atividade parlamentar e o cotidiano da administração pública (Sobottka, 2006, p. 88).

Como observado até aqui, somente a partir da década de 1970 a regulamentação do ECS no Brasil começou a tomar forma, daí esta passou ser uma questão recorrente até o final da primeira década do século XXI, quando certamente ganhou novos contornos - entretanto, não isentos de interpretações distintas e operacionalizações parcimoniosas.

Retomamos 1996, quando é aprovada a LDB (Brasil, 1996a), abolindo os currículos mínimos e estabelecendo as diretrizes e bases da educação nacional. Nesse contexto, mesmo com a área de enfermagem não sentindo a necessidade de nova reformulação, por exigência do Ministério da Educação 
e Cultura (MEC), em 2001, as DCNENFs são construídas e aprovadas pelo MEC, conforme a resolução CNE/CES n. 3, de 2001 (Bagnato e Rodrigues, 2007).

No artigo sétimo, as DCNENFs pontuam que, além dos conteúdos teóricos e práticos, os cursos devem incluir o estágio nos dois últimos semestres, correspondendo a $20 \%$ de sua carga horária total. A esse respeito, Higarashi e Nale (2006) observam que, em termos quantitativos, poder-se-ia afirmar que os estágios ocupam praticamente um quarto da carga horária no processo formativo dos enfermeiros. Com isso, em termos qualitativos, tal modalidade de ensino é apresentada nos cursos de graduação como uma das mais importantes no processo formativo desses profissionais. ${ }^{7}$

No artigo sexto, inciso III, as DCNENFs tratam dos conteúdos essenciais para a formação do enfermeiro, dentre os quais os conteúdos específicos das ciências da enfermagem, orientando que os tópicos de assistência de enfermagem e administração de enfermagem devem ter obrigatoriamente momentos teóricos e práticos. O que deve ser observado é que, além das aulas práticas de laboratório, tem-se outro tipo de aula prática abordada por Backes (2000), que, citando Andrade (1989), destaca a aula prática como um recurso pedagógico, objetivando a aplicação do conteúdo teórico - que visa principalmente ao desenvolvimento de destrezas manuais e à implementação dos conhecimentos obtidos ao longo da formação profissional.

Assim, essa aula prática ocorre nos ambientes 'extramuros' da IES. Tem a finalidade de levar o estudante a realizar a parte prática de determinado conteúdo específico que foi trabalhado em sala de aula por meio de estudos teóricos. Logo, consiste em levar o estudante até as instituições de saúde para que nesse local, acompanhado constantemente pelo docente, aprenda a realizar procedimentos, técnicas e possa ver casos reais de estudos vistos somente na teoria.

Diferentemente do ECS, como destacado anteriormente, as DCNENFs são incisivas ao dizer que, além dos conteúdos teóricos e práticos, os cursos devem incluir o estágio nos dois últimos semestres do curso - devido à necessidade do domínio de conteúdos teóricos e práticos, pois nesse momento o estudante já não terá o docente o acompanhando constantemente.

Esse é o momento em que se espera que o estudante possa inserir-se na realidade, vivenciando a atuação profissional do enfermeiro em seu contexto histórico, político, social, cultural e financeiro, com a tutoria do docente e a supervisão direta do enfermeiro assistente, oportunizando o estudante na construção de conhecimentos, habilidades e valores em articulação com a equipe de enfermagem e de saúde (Amantéa, 2004). Esta mesma autora ainda se reporta aos saberes para tentar esclarecer a diferença entre aula prática e estágio, pois define os saberes práticos em 'saberes sobre a prática', que se referem aos procedimentos e como fazê-los, diretamente relacionados à primeira; e 'saberes da prática' advindos da ação, da experiência - o saber-fazer esse, então, associado ao estágio. 
Tal especificidade do curso de graduação em enfermagem - que deveria ser objeto resolvido, isto é, de convenção aceita por sua clareza e pontualidade - tornou-se âmbito de interpretação dualista entre estágio (saberes da prática) e aula prática (saberes sobre a prática), em que o entendimento sobre o ECS foi muitas vezes colocado no mesmo patamar da aula prática, prejudicando os princípios do estágio, que prevê aproximação do estudante com o campo de trabalho. Solicitava-se, assim, o aprofundamento de estudos nesse contexto, inclusive quanto ao imaginário social de profissionais que militam na enfermagem.

Em 25 de setembro de 2008, entrou em vigor a lei n. 11.788 (Brasil, 2008), que dispõe sobre o estágio de estudantes (conhecida com a 'nova lei de estágio'). Nessa lei, muitas das reivindicações feitas pela academia por meio do Forgrad foram contempladas, consideradas e reconhecidas como elementos indissociáveis do processo de formação profissional inicial ou continuada. Dentre elas destacam-se: a inclusão do plano de atividades no termo de compromisso; a carga horária máxima de estágios semanais; a inclusão tanto do estágio obrigatório como do não obrigatório no projeto pedagógico dos cursos; e a exigência de que a organização concedente e a IES devem designar profissionais responsáveis pela supervisão do estagiário, independentemente da modalidade de estágio.

Essa nova legislação em vigor busca a garantia do estágio como integrante do processo educativo e do projeto pedagógico do curso, bem como almeja reconhecer o estágio como um vínculo educativo-profissionalizante, supervisionado e desenvolvido como parte do projeto pedagógico dos cursos.

Com a aprovação dessa lei, os cursos de enfermagem se veem na obrigação de estudar novamente o estatuto 8 do estágio e se adequar às exigências legais. Nesse sentido, há que se lembrar que, na esteira de discussão, a elaboração dos projetos pedagógicos não poderia ser tangenciada, bem como não poderia ficar à margem das orientações das DCNENFs.

Diante do que foi exposto, pode-se observar que, no processo histórico da profissão do enfermeiro, destacam-se o cuidado com a prática profissional e os modos possíveis de apropriação da identidade desse profissional o que sustenta a necessidade de se discutir como o estágio é compreendido no campo da enfermagem, de como o seu encaminhamento é problematizado, bem como se questionar até que ponto existem encontros e desencontros desse processo formativo com o perfil de profissional exigido pelas DCNENFs.

O ECS dá a oportunidade para o estudante desenvolver competências associadas à aquisição de habilidades, que permitem identificar e adquirir conhecimentos determinantes para ampliar a qualidade da assistência de enfermagem prestada (Dias e Stolz, 2012).

Particularmente no caso dos cursos de graduação em enfermagem, o estágio é o "lócus onde a identidade profissional do aluno é gerada, construída 
e referida; volta-se para o desenvolvimento de uma ação vivenciada, reflexiva e crítica e, por isso, deve ser planejado gradativo e sistematicamente com essa finalidade" (Buriolla, 2009, p. 13). E acrescentamos: é o local do amadurecimento do savoir faire (saber-fazer) necessário para a autonomia interventiva do ator social que optou por determinada área do conhecimento científico.

Felício e Oliveira (2008) afirmam que, para entender a prática como práxis, é preciso assumir a indissolubilidade entre a teoria e a prática. Necessariamente, a área de formação de um indivíduo não pode se caracterizar por uma instrumentalização mecanicista de um trabalho produtivo para a execução, que marginaliza as contribuições epistemológicas historicamente situadas e perpetua a dicotomia entre trabalho material e imaterial.

\section{Conclusão}

O ECS apresenta-se como uma experiência relevante nas situações de aprendizagem, articulando teoria e prática, favorecendo a instrumentalização e a leitura do estudante sobre a área profissional em que está inserido. Assim, a práxis requer movimento, interação e a dialogicidade necessária para o aprofundamento do fazer reflexivo e refletido.

A contribuição do estágio na formação profissional a partir do saber-fazer não se reduz ao conhecimento de um punhado de técnicas e metodologias de ensino, mas amplia-se ao que fazer para a promoção da qualidade da intervenção, resultando numa aprendizagem significativa por conta do aprimoramento e desenvolvimento de habilidades e competências discentes à luz de uma postura crítico-reflexiva.

Especialmente na enfermagem, pode-se inferir que o ECS caracteriza-se como espaço de oportunizações trianguladas pela concreticidade do real profissional - portanto, pontuadas pelas vivências, interações teoria-prática e os enfrentamentos da solicitação de intervenção na área específica do conhecimento. Esse momento é uma possibilidade de reflexão e paralelismo sobre o curso, sobre as solicitações das categorias destinadas à formação - no caso, a de trabalho produtivo -, sobre a interdisciplinaridade e a suficiência ou o aprimoramento necessários à constituição da inteireza profissional.

O estágio, sempre presente na formação do enfermeiro, quando visto como espaço de inserção na constituição do profissional, pode aclarar sobre a certeza ou não da opção do indivíduo quanto à área do conhecimento escolhida; sobre os pontos de tensão e os encaminhamentos para suas resoluções no savoir faire epistemológico e com o coletivo no campo de trabalho; sobre a maturação da intervenção que pode constituir-se no crivo da ação-reflexão-ação; e sobre uma concepção emancipadora de trabalho produtivo em que a interação academia-mundo do trabalho torna-se ainda mais real. 
O ECS, como integrante dos cursos de graduação em enfermagem no Brasil, acontece quando o acadêmico concluiu boa parte da base epistemológica e formação técnica específica, cabendo-lhe utilizar o seu conhecimento para resolver os problemas encontrados, avaliar as diferentes situações que lhe são apresentadas, recuperar a fundamentação científica e tomar decisões que lhe trarão melhores resultados pela transversalização da dimensão ética e de sua contribuição para a coletividade.

A diferença entre campo de estágio e campo de trabalho é que na primeira situação se tem a figura do professor que realiza uma supervisão direta em momentos presenciais e indireta (a distância), orientando as decisões tomadas e as atividades desenvolvidas pelos estagiários e intervindo sobre elas. Já o campo de trabalho é onde o trabalhador desenvolve suas atividades. Não existe a figura do professor, pois o indivíduo deixou de ser estudante, tornando-se um profissional.

Sabemos que ainda são necessárias profundas discussões sobre a aproximação entre trabalho e educação, sobre a promoção de experiências de aprendizagens por meio de leis de estágio, de políticas públicas que garantam a efetivação de direitos do profissional em formação em todas as áreas de conhecimento. Entretanto, entende-se que as mudanças ocorridas - tanto nas orientações sobre o ECS na graduação em enfermagem quanto nas legislações gerais do estágio curricular supervisionado - têm a intenção de garantir sua função educadora, aproximando o aluno do futuro campo de trabalho.

\section{Colaboradores}

Os autores construíram o texto em conjunto, participando de forma integral na elaboração do artigo. 
Resumen El artículo discute las políticas de educación y la pasantía curricular supervisada en el curso de grado en enfermería, la influencia de la restructuración productiva y de la reforma del Estado capitalista en la enseñanza superior brasileña. Por tratarse de un estudio reflexivo, buscó como referencia de discusión la literatura del área, así como las orientaciones recogidas en las legislaciones de la pasantía curricular supervisada y de la enseñanza de enfermería. En el proceso histórico de la profesión de enfermero, se destacan el cuidado con la práctica profesional y los modos posibles de apropiación de la identidad de este profesional. De esta manera, la pasantía se ve como parte indispensable en su proceso de formación; por medio de éste se pueden desarrollar habilidades y competencias propias del enfermero. La pasantía curricular supervisada no debe ser vista sólo como una exigencia del mundo capitalista, pues es posible formar un enfermero capaz de reflexionar sobre sus condiciones materiales de existencia utilizando la práctica reflexiva en la articulación entre enseñanza y servicio.

Palabras clave pasantía curricular; enfermería; políticas de educación.

\section{Notas}

1 Universidade Estadual de Mato Grosso do Sul, Dourados, Mato Grosso do Sul, Brasil. Mestre em Educação pela Universidade Federal da Grande Dourado.

<anamarran@uems.br>

Correspondência: Rua Ranulfo Saldivar, 645, Parque Alvorada, CEP 79823-420, Dourados, Mato Grosso do Sul, Brasil.

2 Universidade Federal da Grande Dourados, Dourados, Mato Grosso do Sul, Brasil. Doutor em Educação Escolar pela Universidade Estadual Paulista Júlio de Mesquita Filho.<paulolima@ufgd.edu.br>

3 Universidade Estadual de Campinas, Campinas, São Paulo, Brasil. Doutora em Educação pela Universidade Estadual de Campinas. <mbagnato@unicamp.br>

4 Este artigo é decorrente de dissertação de mestrado em Educação, de Ana Lúcia Marran, intitulada Avaliação da política de estágio curricular supervisionado: um foco na graduação em enfermagem, apresentada na Faculdade de Educação da Universidade da Grande Dourados, Dourados, Mato Grosso do Sul, em 2012.

5 “Artigo 7. Reforçar a cooperação com o mundo do trabalho e a análise e previsão das necessidades da sociedade: dever-se-ia reforçar e renovar-se os vínculos entre o ensino superior, o mundo do trabalho e outros setores da sociedade; devem as instituições de ensino superior considerar as tendências que ocorrem no mundo do trabalho e nos setores científicos, tecnológicos e econômico objetivando melhorar sua qualidade como fonte permanente de formação, aperfeiçoamento e reciclagem profissional, satisfazendo as demandas no âmbito do trabalho do ensino superior ao mesmo tempo que ao mundo do trabalho, contribuindo para o surgimento de mais e melhores empregos" (Unesco, Conferência Mundial sobre Educação Superior, 1998).

6 Em 1978 acontece a I Conferência Internacional sobre Cuidados Primários de Saúde, promovida pela Organização Mundial da Saúde e pelo Fundo das Nações Unidas para a In- 
fância (Unicef), em Alma-Ata, no Cazaquistão. Neste evento se estabelecem novas orientações para a política de saúde mundial, destacando-se a importância da promoção da saúde e da prevenção de doenças, ações que podem ser feitas indo-se até a comunidade, o que provocaria uma reorganização dos serviços de saúde e a capacitação de recursos humanas para esse tipo de atividade.

7 Notadamente Werneck e colaboradores (2010) sustentam que o principal objetivo do estágio é construir a capacidade de autonomia profissional e política do estudante. Daí a necessidade da construção de uma base epistemológica articulada ao savoir faire com tempo e canais apropriados para a sua discussão, problematização e aprofundamento nos programas de estágios curriculares supervisionados.

8 Aqui utilizamos a palavra estatuto não como termo referente a documento oficial específico, mas no sentido de categoria, status ou papel no contexto do quadro profissional.

\section{Referências}

AMANTÉA, Mara L. Competências do professor do estágio curricular do curso de graduação em Enfermagem segundo a percepção dos próprios docentes. 2004. 113f. Tese (Doutorado em Enfermagem) - Escola de Enfermagem da USP, São Paulo, 2004.

ANDRADE, Maria N. et al. Estágio curricular: avaliação de experiência. Revista Brasileira de Enfermagem, Brasília, v. 42, n. 1, 2, 3 e 4, p. 27-41, jan./dez., 1989.

BACKES, Vânia M. S. Estilo de pensamento e práxis na enfermagem: a contribuição do estágio pré-profissional. Ijuí: Ed. Unijuí, 2000.

BAGNATO, Maria H. S.; RODRIGUES, R. M. Diretrizes curriculares da graduação de enfermagem: pensando contextos, mudanças e perspectivas. Revista Brasileira de Enfermagem, Brasília, v. 60, n. 5, p. 507-512, set./out. 2007.

BARLEM, Jamila G. T. et al. Fragilidades, fortalezas e desafios na formação do enfermeiro. Escola Anna Nery, Rio de Janeiro, v. 16, n. 2, p. 347-353, abr./jun. 2012.
BARREYRO, Gladys B.; ROTHEN, José C. Para uma história da avaliação da educação superior brasileira: análise dos documentos do PARU, CNRES, GERES e PAIUB. Avaliação, Campinas, v. 13, n. 1, p. 131-152, mar. 2008.

BRASIL. Constituição da República Federativa do Brasil (1988). São Paulo: Ediouro, 1988.

BRASIL. Ministério da Educação. Secretaria de Educação Fundamental. Parâmetros Curriculares Nacionais: terceiro e quarto ciclos do Ensino Fundamental - introdução aos Parâmetros Curriculares Nacionais. Brasília: MEC/SEF, 1998.

BRASIL. Ministério da Educação. Conselho Nacional de Educação. Resolução CNE/CP 2/2002. Institui a duração e a carga horária dos cursos de licenciatura, de graduação plena, de formação de professores da Educação Básica em nível superior. Diário Oficial da União, Brasília, 4 de março de 2002. Seção 1, p. 9.

BRASIL. Empresa de Tecnologia e Informações da Previdência Social (Dataprev). Lei 
n. 8.859, de 23 de março de 1994. Disponível em: <www3.dataprev.gov.br/SISLEX/paginas/ 42/1994/8859.htm>. Acesso em: 28 out. 2010.

BRASIL. Ministério da Educação. Conselho Nacional de Educação. Lei n. 9.394, de 20 de dezembro de 1996. Estabelece as diretrizes e bases da educação nacional. Diário Oficial da União. Brasília, seção 1, 23 de dez. 1996a. p. 27.833.

BRASIL. Decreto n. 2.080, de 26 de novembro de 1996b. Disponível em: <http://presrepublica. jusbrasil.com.br/legislacao/112127/decreto2080-96>. Acesso em: 28 out. 2010.

BRASIL. Ministério Público do Trabalho. Notificação recomendatória n. 741/2002. Brasília, 2002. Disponível em: <www. maua.br/arquivos/index/h/f61e854e702cd9 26def819a754d17563>. Acesso em: 28 out. 2010 .

BRASIL. Ministério da Educação. Conselho Nacional de Educação. Câmara de Educação Superior. Resolução CNE/CES n. 3, de 7 de novembro de 2001. Institui Diretrizes Curriculares Nacionais do curso de graduação em Enfermagem. Diário Oficial da União. Brasília, 9 de Nov. 2001, Seção 1, p. 37.

BRASIL. Ministério Público do Trabalho. Lei n. 6.494, de 7 de dezembro de 1977. Dispõe sobre os estágios de estudantes de estabelecimentos de ensino superior e de ensino profissionalizante do $2^{\circ}$ grau e supletivo e dá outras providências. Diário Oficial da União. Brasília, 9 dez. 1977.

BRASIL. Decreto n. 87.497, de 18 de agosto de 1982. Regulamenta a lei n. 6.494, de 7 de dezembro de 1977, que dispõe sobre o estágio de estudantes de estabelecimentos de ensino superior e de $2^{\circ}$ grau regular e supletivo, nos limites que especifica e dá outras providências. Disponível em: <www. planalto.gov.br/ccivil_03/decreto/d87497. htm >. Acesso em: 28 out. 2010.

BRASIL. Ministério do Trabalho e Emprego. Lei n. 11.788, de 25 de setembro de 2008. Dispõe sobre o estágio de estudantes e dá ou- tras providências. Diário Oficial da União. Brasília, 26 de set. 2008. Disponível em: <www.planalto.gov.br/ccivil_03/_Ato2007 -2010/2008/Lei/L11788.htm>. Acesso em: 15 mar. 2009.

BURIOLLA, Marta A. F. O estágio supervisionado. 6. ed. São Paulo: Cortez, 2009.

CAMARGO, Arlete M. M. O princípio da flexibilização curricular nos currículos dos cursos de graduação. In: CHAVES, Vera L. J.; CABRAL NETO, Antonio; NASCIMENTO, Ilma V. (Org.) Politicas de educação superior no Brasil: velhos tempos novos desafios. São Paulo: Xamã, 2009. p. 211-225.

COMISSÃO NACIONAL DE ESTÁGIO DO FÓRUM DE PRÓ-REITORES DE GRADUAÇÃO DAS UNIVERSIDADES BRASILEIRAS (FORGRAD). Gestão administrativa e pedagógica do estágio. In: ENCONTRO NACIONAL DE ESTÁGIOS, 3, 2004, Campinas. Anais eletrônicos. Campinas: Unicamp, 2004.

COSTA, Lauriana M.; GERMANO, Raimunda M. Estágio curricular supervisionado na graduação em Enfermagem: revisando a história. Revista Brasileira de Enfermagem, Brasília, v. 60, n. 6, p. 706-10, 2007.

DIAS, Denise G.; STOLZ, Pablo V. Projeto de extensão "Vivências para acadêmicos de enfermagem no Sistema Único de Saúde" na perspectiva do acadêmico. Journal of Nursing and Health, Pelotas, v. 2, n. 2, p. 440-445, 2012.

DOURADO, Luiz F.; CATANI, Afrânio M.; OLIVEIRA, João F. Transformações recentes e debates atuais no campo da educação superior no Brasil. In: DOURADO, Luiz F.; CATANI, Afrânio M.; OLIVEIRA, João F. (Org.). Políticas e gestão da educação superior: transformações recentes e debates atuais. São Paulo: Xamã; Goiânia: Alternativa, 2003. p. 17-30.

FELÍCIO, Helena M. S.; OLIVEIRA Ronaldo A. A formação prática de professores no estágio curricular. Educar, Curitiba, n. 32, p. 215-232, 2008. 
FERRETTI, Celso J.; SILVA JÚNIOR, João R. Educação profissional numa sociedade sem empregos. Cadernos de Pesquisa, São Paulo, São Paulo, n. 109, p. 43- 66, mar. 2000.

FOGAÇA, Azuete. Educação e qualificação profissional nos anos 90: o discurso e o fato. In: OLIVEIRA, Dalila A.; DUARTE, Marisa. R. T. (Org.). Politica e trabalho na escola: administração dos sistemas públicos de educação básica. Belo Horizonte: Autêntica, 1999. p. 55-68.

FONSECA, Marília. O Banco Mundial e a Educação: reflexões sobre o caso brasileiro. In: GENTILI, Pablo. (Org.). Pedagogia da exclusão: o neoliberalismo e a crise da escola pública. 13. ed. Petrópolis: Vozes, 2007. p. 169-195

FRIGOTTO, Gaudêncio; CIAVATTA, Maria. Educação básica no Brasil na década de 1990: subordinação ativa e consentida à lógica do mercado. Educação \& Sociedade. Campinas, v. 24, n. 82, p. 93-130, abr. 2003.

GERMANO, Raimunda M. Educação e ideologia da enfermagem no Brasil. 3. ed. São Paulo: Cortez, 1993.

GERMANO, Raimunda M. O ensino de enfermagem em tempos de mudança. Revista Brasileira de Enfermagem, Brasília, v. 56, n. 4, p. 365-368, 2003.

GOMES, Jomara B. Autoavaliação: um caminho para a formação do profissional crítico-reflexivo na Enfermagem. 2001. 279p. Tese (Doutorado em Enfermagem) - Escola de Enfermagem, São Paulo, 2001.

GONDIM, Sônia M. G. Perfil profissional e mercado de trabalho: relação com a formação acadêmica pela perspectiva de estudantes universitários. Estudos de Psicologia, Natal, v. 7, n. 2, p. 299-309, 2002.

HIGARASHI, Ieda H.; NALE, Nivaldo. O estágio supervisionado de enfermagem em hospitais como espaço de ensino-aprendizagem: uma avaliação. Ciência, Cuidado e Saúde, Maringá, v. 5, supl., p. 65-70, 2006.
KRAWCZYK, Nora R.; VIEIRA, Vera L. A reforma educacional na América Latina nos anos 1990: uma perspectiva histórico-sociológica. São Paulo: Xamã, 2008.

KUENZER, Acacia Z. Ensino médio e profissional: as políticas do Estado neoliberal. 3. ed. São Paulo: Cortez, 2001.

LIMA, Paulo G. Politica científica e tecnológica no Brasil no governo Fernando Henrique Cardoso (1995-1998). Dourados: Editora da UFGD, 2011 a.

LIMA, Paulo G. Políticas educacionais e universidade no Brasil no contexto da reestruturação produtiva e reforma do estado. In: CONGRESSO IBERO-AMERICANO DE POLÍTICA E ADMINISTRAÇÃO DA EDUCAÇÃO, 2., 2001, São Paulo. Anais... São Paulo. Políticas Públicas e Gestão da Educação: construção histórica, debates contemporâneos e novas perspectivas. São Paulo, SP, 26 a 30 de abril, 2011 b.

LOPES, Márcia M. R. A articulação das politicas públicas de educação e de saúde na voz de egressos: análise da formação de enfermeiros, em Dourados-MS. 2011. 190f. Dissertação (Mestrado em Educação) - Faculdade de Educação, UFGD, Dourados, 2011.

OLIVEIRA, Dalila A. As reformas em curso nos sistemas públicos de educação básica: empregabilidade e equidade social. In: OLIVEIRA, Dalila A.; DUARTE, Marisa R. T. (Org.). Política e trabalho na escola: administração dos sistemas públicos de educação básica. Belo Horizonte: Autêntica, 1999. p. 69-97.

PIMENTA, Selma G. O estágio na formação de professores: unidade teoria e prática? 9. ed. São Paulo: Cortez, 2010.

RAMÃO, José E. Globalização e reforma educacional no Brasil (1985-2005). In: TEODORO, Antônio (Org.). Tempos e andamentos nas políticas de educação: estudos iberoamericanos. Brasília: Líber Livros; CYTED, 2008. p. 163-186. 
ROTHEN, José C. Funcionário intelectual do Estado: um estudo de epistemologia política do Conselho Federal de Educação. 2004. 270 p. Tese (Doutorado em Educação) Universidade Metodista de Piracicaba, Faculdade de Educação, 2004.

SEGNINI, Liliana R. P. Educação e trabalho: uma relação tão necessária quanto insuficiente. São Paulo em Perspectiva, São Paulo, v. 14, n. 2, p. 72-81, 2000.

SHIROMA, Eneida O.; MORAES, Maria C. M.; EVANGELISTA, Olinda. Política educacional. Rio de Janeiro: Lamparina, 2007.

SILVA JUNIOR, João R. Mudanças estruturais no capitalismo e a política educacional do governo FHC: o caso do ensino médio. Educação \& Sociedade, Campinas, v. 23, n. 80 , p. 203-234, set. 2002.

SIQUEIRA, Ângela C.; NEVES, Lucia M. W. (Org.). Educação superior: uma reforma em processo. São Paulo: Xamã, 2006.

SOBOTTKA, Emil A. Por que se faz políticas sociais no Brasil?. Revista de Ciências Sociais, Porto Alegre, v. 6, n. 1, p. 79 - 93, jan./jun, 2006.
SOUZA, Tatiana M. C. Intersubjetividade na formação profissional: a experiência do estágio supervisionado em serviço social no centro jurídico social da Faculdade de História, Direito e Serviço Social da Unesp/Franca. 2009. 194f. Dissertação (Mestrado em Serviço Social) - Faculdade de História, Direito e Serviço Social, Universidade Estadual Paulista "Júlio de Mesquita Filho", Franca, 2009.

UNESCO. CONFERENCIA MUNDIAL SOBRE LA EDUCACION SUPERIOR. La educación superior en el siglo XXI: Visión y acción. Paris: Unesco, 1998. Disponível em: <www. unesco.org/education/educprog/wche/ declaration_spa.htm $>$. Acesso em: 10 set. 2011.

XAVIER, Maria E. S. P.; DEITOS, Roberto A. Estado e política educacional no Brasil. In: DEITOS, Roberto Antônio; ROGRIGUES, Rosa M. Estado, desenvolvimento, democracia e politicas sociais. Cascavel: EDUNIOESTE, 2006. p. 67-86.

WERNECK, Marcos A. F. et al. Nem tudo é estágio: contribuições para o debate. Ciência \& Saúde Coletiva, Rio de Janeiro, v. 15, n. 1, p. 221-231, 2010.

Recebido em 24/05/2013

Aprovado em 08/10/2013 